\title{
GESTÃO ESTRATÉGICA DE CUSTOS: UMA INTERVENÇÃO APLICADA A UM POSTO DE COMBUSTÍVEL
}

\author{
Bruna Fernanda Dias ${ }^{1}$ \\ Amanda Grapégia ${ }^{2}$ \\ Ketlyn da Silva Pasquali ${ }^{3}$ \\ Luiz Gustavo Santos Barboza ${ }^{4}$ \\ Delci Grapégia Dal Vesco ${ }^{5}$
}

DIAS, B. F.; GRAPÉGIA, A.; PASQUALI, K. da S.; BARBOZA, L. G. S.; DAL VESCO, D. G. Gestão estratégica de custos: uma intervenção aplicada a um posto de combustível. Rev. Ciênc. Empres. UNIPAR, Umuarama, v. 19, n. 1, p. 57-70, jan./jun. 2018.

RESUMO: O artigo versa sobre o tema gestão estratégica de custos e tem como objetivo apresentar os resultados de uma proposta de intervenção aplicada na gestão de custos sob a perspectiva da implementação do custo-meta no posto de combustível Alfa. Para tanto o referencial teórico versou sobre Sistema de Gestão de Custos, Custo-meta e franchising. Como metodologia foi utilizada a intervenção realizada no posto de combustível objeto de estudo. Foi identificado após verificação o histórico mensal dos resultados do ano de 2016, prejuízo em todo o período. Após a revisão dos impostos pagos, identificou-se que a organização estava realizando desembolsos para pagamento de impostos indevidos, o que ocorria em função da dificuldade em lançamento de despesas específicas, o que impediam a redução de lucro antes do cálculo de Imposto, gerando em um custo tributário maior que o devido. Após a intervenção, a organização reverteu seu quadro negativo e passou a apresentar lucro em seu resultado. Como sugestão de pesquisas futuras é a aplicação do custo meta no posto de combustível, bem como revisão contratual com base na teoria dos contratos.

PALAVRAS-CHAVE: Intervenção organizacional; Custos; Posto de combustível.

DOI: $10.25110 /$ receu.v19i1.6547

${ }^{1}$ Universidade Estadual do Oeste do Paraná - Unioeste - Cascavel, Paraná, Brasil. brunafernandadiass@gmail.com.

${ }^{2}$ Universidade Estadual do Oeste do Paraná - Unioeste - Cascavel, Paraná, Brasil. amandagrapegia97@gmail.com

${ }^{3}$ Universidade Estadual do Oeste do Paraná - Unioeste - Cascavel, Paraná, Brasil. ketlyn pasquali@, hotmail.com 


\title{
STRATEGIC COST MANAGEMENT: AN INTERVENTION APPLIED TO A GAS STATION
}

\begin{abstract}
The paper addresses the topic of strategic cost management, and aims at presenting the results of an intervention proposal applied to cost management from the perspective of implementation of target costing at the Alfa gas station. For such, theoretical reference on Cost Management System, Target Costing and franchising was used. The intervention performed at the gas station was used as the methodology. After checking the monthly history of results for 2016, a loss was observed in the entire period. After reviewing the taxes paid, it was identified that the organization was making disbursements for paying undue taxes, which took place due to the difficulty in launching specific expenses, which prevented the deduction of profit before calculating the taxes, generating a higher tax cost. After the intervention, the organization reversed its negative status and started to present profit in its result. The application of target costing in the gas station is suggested for further research, as well as the contractual review based on the theory of contracts.
\end{abstract}

KEYWORDS: Costs; Gas station; Organizational intervention.

\section{GESTIÓN ESTRATÉGICA DE COSTOS: UNA INTERVENCIÓN APLICADA A UNA GASOLINERA}

RESUMEN: El artículo versa sobre el tema gestión estratégica de costos, objetivando presentar los resultados de una propuesta de intervención aplicada en la gestión de costos bajo la perspectiva de implementación del costo meta en la gasolinera Alfa. Para tanto, el referencial teórico versó sobre Sistema de Gestión de Costos, Costo meta y franchising. Como metodología se utilizó la intervención realizada en la gasolinera objeto de estudio. Se identificó después de verificar el histórico mensual de los resultados del año 2016, perjuicio en todo el período. Tras la revisión de los impuestos pagados, se identificó que la organización estaba realizando desembolsos para el pago de impuestos indebidos, lo que ocurría en función de la dificultad en la contabilización de gastos específicos, lo que impedía la reducción de ganancia antes del cálculo del Impuesto, generando un costo tributario mayor que el debido. Después de la intervención, la organización revertió su cuadro negativo y pasó a presentar ganancias en su resultado. Como sugerencia de investigaciones futuras es la aplicación del costo meta en la gasolinera, así como la revisión contractual basada en la teoría de los contratos.

PALABRAS CLAVE: Costos; Intervención organizacional; Gasolinera. 


\section{INTRODUÇÃO}

O contexto em que as organizações se inserem está cada vez mais dinâmico e hostil, sendo que, esse dinamismo está associado às mudanças de tecnologias de materiais, processos e produtos, à internacionalização, bem como, à abertura dos limites geográficos ao comércio e investimentos, proporcionando novas oportunidades às empresas e acarretando na crescente competitividade (LAUSCHNER; BEUREN, 2004; FERREIRA; BUFONI, 2006).

À medida em que a concorrência se intensifica, ela alimenta a corrida entre os concorrentes para atender clientes globalizados, gera economias de escala, explora os potenciais de redução de custos e melhoria da qualidade (LAUSCHNER; BEUREN, 2004).

Assim, para uma organização manter-se competitiva e próspera, necessita estar atenta à dinâmica do mercado, bem como criar condições para que, internamente, os vários atores organizacionais ajam de maneira sincrônica, no sentido de conduzir a instituição para a mesma direção (SILVA et al., 2014).

Essa sintonia com o mercado e a busca por vantagens competitivas tem sido a perspectiva incessante dos postos de combustíveis, objeto de estudo dessa pesquisa. Até a década de 1990, o mercado de combustíveis do Brasil foi marcado por excessiva intervenção estatal, em que os preços eram regulados e utilizados como ferramenta macroeconômica, no sentido de conter o avanço do processo inflacionário (LEITE; LANZER; RIBEIRO SERRA, 2009).

Ainda, a indústria brasileira de combustíveis até 1993 foi caracterizada por contratos exclusivos entre distribuidoras e revendedoras, ou seja, cada revendedora obrigatoriamente estabelecia um contrato de exclusividade com uma distribuidora e apenas adquiria combustível dessa distribuidora (PINTO; SILVA, 2008).

No entanto, a partir de 1993, iniciou-se um processo de desregulamentação na estrutura concorrencial brasileira de combustíveis, que proporcionou como consequência o surgimento do revendedor de bandeira branca e alterou o cenário: práticas irregulares foram facilitadas e a precificação, que até 1997 era fixada pelo Ministério da Fazenda, foi flexibilizada, passando a ser definida pela concorrência (PINTO; SILVA, 2008; LEITE; FIATES; LIMA, 2013).

Nesse sentido, Cruz e Rocha (2008) afirmam que a concorrência nacional e internacional e a variedade de produtos são alguns dos fatores que propicam um ambiente de alta competitividade e forçam uma mudança de metodologia por parte das empresas no cálculo dos seus preços de venda, ou seja, o preço médio de venda dado pelo mercado é que define o custo do produto, sendo esse custo chamado de custo-meta. Além disso, Araújo et al. (2004) discorrem sobre o custo-meta como um método que não atua como uma simples técnica de redu- 
ção de custos, mas também, como um completo sistema de gestão estratégica de benefícios.

Dessa forma, diante dessas circunstâncias, os postos de combustíveis (principalmente os bandeirados/franqueados) precisam alterar sua gestão estratégica de custos a fim de manterem suas atividades. Diante disso, o desenvolvimento dessa pesquisa é resultado de uma consultoria realizada para um posto de combustível franqueado. Trata-se de uma empresa de pequeno porte, que está no mercado desde 1996, localizada na região Central de Cascavel, Paraná.

Sendo assim, o presente estudo buscou responder a seguinte questão de pesquisa: Quais os resultados da proposta de intervenção na gestão de custos sob a perspectiva da implementação do custo-meta no posto de combustível Alfa?

Com o intuito de responder a questão de pesquisa, o objetivo desse artigo é apresentar os resultados de uma proposta de intervenção aplicada na gestão de custos sob a perspectiva da implementação do custo-meta no posto de combustível Alfa.

Ainda, Pinto e Silva (2008) reiteram que a maioria dos trabalhos encontrados sobre o mercado brasileiro de combustível faz uma análise de fatores como o processo de desregulamentação, dos fatos históricos que motivaram o início da desregulamentação e da mudança na estrutura tributária.

Destarte, a contribuição técnica dessa pesquisa está em corroborar a discussão acadêmica envolvendo o segmento, evidenciando, na prática, possíveis resoluções às consequências advindas da gestão de custos, bem como, no diagnóstico realizado na empresa, retratando um tema estratégico para a organização que possibilita melhoria da gestão, redução de custos e, consequentemente, aumento de receitas e o aprimoramento da competitividade.

Esse artigo está estruturado em seções. Após essa introdução, apresenta-se a fundamentação teórica; em seguida, o terceiro tópico retrata o método, contexto da situação-problema e intervenção realizada; a quarta seção desenvolve sobre a apresentação e análise das contribuições; e, por fim, a quinta seção relata as considerações finais.

\section{FUNDAMENTAÇÃO TEÓRICA}

Nessa seção apresentam-se conceitos da literatura que contribuíram para as intervenções realizadas no posto de combustível. Sendo assim, relatou-se os tópicos sistema de gestão de custos, custo-meta, bem como franquias (franchising).

\subsection{Sistema de Gestão de Custos}

A gestão de custos coleta, classifica, mensura e identifica as informa- 
ções que são importantes para os gestores, no que tange ao custeio, planejamento e tomada de decisão. Para que haja essa gestão de custos, deve-se ter conhecimento de todos os custos da organização, e principalmente saber agrupá-los entre curto e longo prazo. Dessa forma, um sistema de gestão de custos é composto por dois subsistemas - contabilidade de custos e controle operacional (HANSEN; MOWEN, 2001).

O crescimento da área de gestão de custos se deu graças a competitividade mundial, os avanços da tecnologia de informação, o crescimento no setor de serviços e os avanços no ambiente de manufatura que fizeram com que os empresários mudassem a forma de exercer seus negócios (HANSEN; MOWEN, 2001). Assim, o foco do sistema de gestão de custos foi ampliado para melhor atender as necessidades dos clientes e coordenar a cadeia de valores das empresas.

Ainda, um sistema de gestão de custos é composto por dois subsistemas: contabilidade de custos e controle operacional e pode estar ligado às vantagens competitivas das empresas (HANSEN; MOWEN, 2001; MELO; LEONI, 2015). Além disso, Melo e Leoni (2015) afirmam que a organização deve assumir uma posição adequada para alcançar essas vantagens em relação aos concorrentes, e para isso deve-se utilizar a mensuração dos custos, tanto na diferenciação quanto no estoque.

Dessa forma, os custos necessitam ser tratados como elementos estratégicos, já que alguns dos objetivos da empresa só podem ser alcançados por meio de um sistema de gestão de custos eficiente.

Ademais, há a necessidade de estruturar um sistema de custo na organização, mas para isso não é preciso analisar e mensurar todos os gastos, visto que "qualquer entidade que pretende medir tudo acaba não medindo nada" (OLIVEIRA, 2016, p. 126), ou seja, o que realmente precisa para a gestão de custos nas empresas são informações concretas e confiáveis que viabilizem o controle, a análise e a tomada de decisão de maneira oportuna.

Assim, o objetivo de um sistema de gestão de custos é melhorar a qualidade, o conteúdo e a relevância dos custos (HANSEN; MOWEN, 2001). Para tanto, dois cálculos são mais aplicados pelos gestores de custos: a margem de contribuição e o ponto de equilíbrio, os quais serão relatados na sequência.

\subsubsection{Margem de Contribuição}

Para Martins (2006) o mercado é responsável pela fixação do preço de custos e não o custo de produção, como é do senso comum, por esta razão a maximização de lucro é o objetivo da gestão de custo. A margem de contribuição, a grosso modo, pode ser considerada a "sobra" que a empresa tem para poder fazer o pagamento das despesas fixas e mesmo assim obter um lucro. É representada pela fórmula (1). 
Fórmula 1: Margem de contribuição.

$\mathrm{MC}=\mathrm{RV}-(\mathrm{CD}+\mathrm{DD})$

Onde:

$\mathrm{MC}=$ margem de contribuição

$\mathrm{RV}=$ receita de vendas

$\mathrm{CD}=$ custo direto

$\mathrm{DD}=$ despesa direta

Fonte: Martins (2006).

Para Passareli e Bomfim (2003, apud REDIVO, 2004) a margem de contribuição tem grande importância para a avaliação das características financeiras de um determinado produto - seja de um já existente ou de um novo produto - e dessa forma contribui na tomada de decisão.

\subsubsection{Ponto de Equilíbrio}

Conhecido também como ponto de partida ou ponto de nivelamento, o ponto de equilíbrio é o "nível de produção e comercialização de produtos e serviços em que o resultado é nulo", isto é, quanto o faturamento ou o total das vendas são suficientes para cobrir os custos e despesas, sem gerar lucro ou prejuízo (RAIMUNDI; ZUCATTO; BIANCHI, 2008, p. 42). É representado pela fórmula (2).

Fórmula 2: Margem de contribuição.

$\mathrm{RT}=(\mathrm{CF}+\mathrm{CV})$

Onde:

$$
\begin{aligned}
& \mathrm{RT}=\text { receita total } \\
& \mathrm{CF}=\text { custo total } \\
& \mathrm{CV}=\text { custo variável }
\end{aligned}
$$

Fonte: Raimundi; Zucatto; Bianchi (2008, p. 42)

\subsection{Custo Meta}

O custo meta, que surgiu no Japão em 1970, foi adotado inicialmente para a prática de produção de software e em indústrias montadoras e de transformação. Uma década depois, esta forma de custeio foi aplicada em estratégia empresarial e assim, com o intuito de alcançar o lucro desejado, tornou-se um instrumento de gerenciamento estratégico de custos. Esse custo é indicado principalmente para organizações que possuem alto nível de tecnologia de produção e produtos com ciclo de vida curto e com baixo volume de produção acabada (CARASTAN, 1999).

O principal objetivo do custo meta é a redução do custo total e, ainda, 
conforme Carastan (1999) pode ser também uma fórmula para achar um lucro-meta, ou até mesmo um planejamento de retorno sobre as mercadorias vendidas, ou seja, um planejamento de lucro com a finalidade de reduzir os custos totais, sem perder a qualidade dos produtos. Esse cálculo é feito utilizando como base o custeio de absorção, o qual se apropria de todos os custos de produção do produto. Para isso, deve se ter um conhecimento prévio de todos os custos que serão alocados separadamente, iniciando, então, pelos custos diretos e, em seguida, os custos diretos de transformação e os custos indiretos de transformação.

Cruz e Rocha (2008, p. 37) afirmam que o custo meta, ou o custo-alvo, é o "montante de custos a ser eliminado ou, se necessário, aumentado, para que o custo estimado de um produto ou serviço se ajuste ao admissível, tendo em vista o custo total do consumidor, o preço-alvo e as margens-alvo para cada elo da cadeia". De forma mais acessível, é a diferença entre o custo estimado e o máximo permitido (CAMACHO; ROCHA, 2006).

Cruz e Rocha (2008) expõem alguns princípios fundamentais característicos do custeio-alvo:

a) O preço do mercado que define o custo do produto, e não o contrário;

b) O foco está, totalmente, no cliente;

c) Deve haver uma abrangência interfuncional - ligação entre várias áreas - dentro da organização;

d) A diretriz é o ciclo de vida do produto, tendo em vista o custo total do consumidor;

e) Deve-se levar em conta a cadeia de valor.

Para que o custo meta seja demandado são necessários alguns requisitos, que servem como condições para que o processo tenha sucesso, sendo eles: envolvimento infraestrutural, orientação para o ciclo de vida do produto e um envolvimento com a cadeia de valor (CRUZ; ROCHA, 2008).

\subsection{Franquias (franchising)}

Recebe também o nome de franchising e representa todos os complexos de franqueados, franqueador, produtos e serviços. De acordo com Lavieri, Correa e Cunha (2015) esse termo representa "um direito ou privilégio de operar conforme a estrutura preconcebida do franqueador", isso ocorre por meio de um contrato entre duas empresas distintas, e assim, o franqueado paga ao franqueador esse direito de utilizar a marca por um certo tempo.

Além do direito de utilizar a marca, Paulino (2010) afirma que o franchising dá ao franqueado outros benefícios, como: exclusividade ou semiexclusividade de produtos ou serviços, tecnologia de implantação e administração de negócios e sistema operacional. Para Hitt et al. (2011) o termo é uma estratégia de cooperação em que o franqueador utiliza a franquia como relação contratual 
para controlar o compartilhamento de seus recursos e capacitações com os franqueados.

Dentro das franquias quem formula, aperfeiçoa e controla os projetos estratégicos, na visão de Paulino (2010), é o franqueador, sendo que o franqueado tem a função apenas de executar o projeto. Para amenizar os conflitos e equilibrar os interesses, o franqueador deve implantar algumas medidas, tais como: desenvolvimento de programas, treinamentos, planejar encontros entre os franqueados, implantação de um conselho de publicidade e de comunicação, supervisão frequente de todos os franqueados, visão de um possível prejuízo, além de prestar suporte operacional e de gestão (MAURO, 2006).

\section{MÉTODO, CONTEXTO DA SITUAÇÃO-PROBLEMA E INTERVEN- ÇÃO REALIZADA}

Essa seção destina-se apresentar o procedimento da intervenção realizada no posto de combustível objeto de estudo, evidenciando os achados da situação atual da empresa e, em seguida, após a execução das novas práticas de gestão sugeridas.

Os postos de combustíveis lidam com a concorrência acirrada no setor, seja com os concorrentes que são franqueados ou os que não utilizam uma marca específica de combustível. Os postos que não são franqueados possuem vantagem competitiva no preço de venda devido a adquirirem o combustível de qualquer revendedor, o que ocasiona em menor custo do produto.

Dessa maneira, a empresa em estudo é franqueada de uma rede que fornece todo o combustível disponilizado para comercialização pelo empreendimento. De acordo com a administrição da empresa, optou-se em ser franqueado devido ao suporte que a franquia disponibiliza aos revendedores tais como: "a montagem do empreendimento e, em caso de algum acidente relacionado com a armazenagem do combustível, há auxílio da franqueadora, pois a franqueadora (distribuídora) é comprometida em criar estratégias de negócios com foco nos pilares de sustentabilidade, bem como a possibilidade de ter "Postos Ecoeficientes", esses postos têm o objetivo de adequar as instalações de um posto de abastecimento (do planejamento da obra à operação) à preservação dos recursos naturais, de forma economicamente viável, trazendo mais eficiência e redução de custos operacionais com consumo de energia e agua, respeito à legislação brasileira e órgãos regulatórios, a franqueada possui uma política de atender às expectativas e necessidades de nossos clientes, garantindo um contínuo aperfeiçoamento dos produtos e serviços, por meio do elevado padrão de qualidade de produtos e serviços reconhecida por nossos cliente". Ademais, na época que assinei o contrato a diferença do custo entre a franqueadora e uma distribuídora bandeira branca era de 6 (seis centavos) e entre as distribuidoras concorrentes 
era zero.

Por outro lado, os custos em ser franqueado são maiores e a margem de lucro por litro de combustível é menor. Além disso, os postos praticam preços de revenda de combustíveis de acordo com o mercado, ou seja, acompanham os preços empregados pela concorrência para se manterem no mercado competitivo.. Sendo assim, na sequência o Quadro 1 detalha a margem de contribuição por litro de combustível que se refere à maio de 2017.

\section{RESULTADOS E DISCUSSÃO}

Quadro 1: Margem de contribuição por litro de combustível

\begin{tabular}{|l|c|c|c|c|}
\hline \multicolumn{1}{|c|}{ Combustível } & Diesel & Àlcool & Gasolina Aditivada & Gasolina Comum \\
\hline Preço de venda & $\mathrm{R} \$ 3,07$ & $\mathrm{R} \$ 2,59$ & $\mathrm{R} \$ 3,75$ & $\mathrm{R} \$ 3,65$ \\
\hline Custos variáveis (-) & $\mathrm{R} \$ 2,54$ & $\mathrm{R} \$ 2,29$ & $\mathrm{R} \$ 3,28$ & $\mathrm{R} \$ 3,23$ \\
\hline Margem de contribuição & $\mathrm{R} \$ 0,53$ & $\mathrm{R} \$ 0,30$ & $\mathrm{R} \$ 0,47$ & $\mathrm{R} \$ 0,42$ \\
\hline Margem de contribuição percentual & $17,2 \%$ & $11,5 \%$ & $12,5 \%$ & $11,05 \%$ \\
\hline
\end{tabular}

Fonte: dados da pesquisa (2017).

Conforme apresentado no Quadro 1, apresenta-se a margem de contribuição de cada combustível, e indica quanto cada produto contribui para o resultado global da empresa. Assim, ao identificar o preço de venda unitário subtrai-se o custo de cada combustível para obter a margem de contribuição, e o resultado divide-se pelo preço de venda para obter a margem de contribuição percentual.

Dessa maneira, observa-se que a margem de contribuição apresentada é baixa e que se ganha pela quantidade vendida. Com isso, devido à instabilidade econômica somando-se às altas despesas para manter as atividades no posto de combustível, a organização apresentou resultados negativos no exercício de 2016, segundo evidenciado em Quadro 2.

Quadro 2: Resultados mensais do exercício de 2016

\begin{tabular}{|l|c|c|c|c|c|c|c|c|c|c|c|c|}
\hline Meses & Jan. & Fev. & Mar & Abr. & Mai. & Jun. & Jul. & Ago. & Set. & Out. & Nov. & Dez. \\
\hline Receita Operacional Bruta & 70 & 72 & 69 & 74 & 81 & 78 & 76 & 81 & 70 & 75 & 79 & 84 \\
\hline Despesas & 87 & 87 & 96 & 94 & 93 & 89 & 90 & 106 & 96 & 89 & 115 & 106 \\
\hline Lucro & -17 & -15 & -27 & -20 & -12 & -11 & -14 & -25 & -26 & -14 & -36 & -22 \\
\hline
\end{tabular}

Fonte: dados da pesquisa (2017)

Verifica-se no Quadro 2 a receita operacional bruta substraindo-se as despesas apresentando o lucro. Com isso, o empreendimento apresentou prejuízo no exercício de 2016, ocasionando dificuldades para a continuidade do negócio.

Por meio disso, indagou-se à administração quanto ao pagamento de impostos de acordo com a tributação enquadrada (lucro real), de modo que, mesmo com prejuízos, a organização desenbolsava com pagamento de tributos. Des- 
sa maneira, buscou-se identificar as causas para pagamento de tributo que não era devido. Conforme relatado pela gestora, algumas despesas não eram utilizadas para comprovar para dedução do lucro bruto e, assim, apresentavam um lucro fictício resultando no pagamento de impostos indevidos.

Após a entrevista com a administração, foi proposto um método de apresentar despesas para redução do lucro antes do cálculo do imposto como forma de aumentar as despesas. Assim, observou-se que não eram enviadas as taxas e gastos com a utilização do cartão de crédito, sendo que, a partir dessa empregabilidade, acarretou na melhora do resultado nos três meses subsequentes do ano de 2017, conforme demonstrado no Quadro 3.

Quadro 3: Resultados mensais para o exercício de 2017

\begin{tabular}{|l|c|c|c|c|}
\hline \multicolumn{1}{|c|}{ Meses } & Janeiro & Fevereiro & Março & Abril \\
\hline Receita operacional bruta & $\mathrm{R} \$ 73.706,94$ & $\mathrm{R} \$ 84.799,50$ & $\mathrm{R} \$ 98.761,77$ & $\mathrm{R} \$ 95.907,48$ \\
\hline Despesas & $\mathrm{R} \$ 85.860,46$ & $\mathrm{R} \$ 75.425,33$ & $\mathrm{R} \$ 86.261,79$ & $\mathrm{R} \$ 84.687,38$ \\
\hline Lucro & $\mathrm{R} \$(13.153,52)$ & $\mathrm{R} \$ 9.374,17$ & $\mathrm{R} \$ 12.499,98$ & $\mathrm{R} \$ 11.220,10$ \\
\hline
\end{tabular}

Fonte: dados da pesquisa (2017)

O Quadro 3 apresenta a receita operacional bruta subtraindo-se as despesas, para identificação do lucro. Como se evidencia, a empresa teve prejuízo apenas no mês de janeiro, sendo que, nos meses subsequentes, apresentou resultados positivos de acordo com a intervenção realizada e observação da gestão em contabilizar as despesas financeiras anteriormente desconsideradas.

Como o custo meta, apresenta suas especificidades a serem atendidas Cruz e Rocha (2008) expõem alguns princípios fundamentais característicos do custeio-alvo, os quais foram investigados nessa pesquisa:

a) o preço do mercado que define o preço do produto comercializado, e não o custo de aquisição, o Quadro 4 mostra o preço da concorrência na cidade local em que o posto está instalado:

Quadro 4: Preço de mercado, revendedor - dados do mercado

\begin{tabular}{|l|c|c|c|c|}
\hline Combustível & Diesel & Álcool & Gasolina Comum & Gasolina Aditivada \\
\hline Franqueadora concorrente 1 & 2,79 & 2,49 & 3,49 & 3,67 \\
\hline Franqueadora concorrente 2 & 2,79 & 2,49 & 3,49 & 3,67 \\
\hline Bandeira Branca & 2,77 & 2,39 & 3,39 & 3,44 \\
\hline Posto em estudo & 2,94 & 2,54 & 3,56 & 3,64 \\
\hline
\end{tabular}

Fonte: dados da pesquisa Julho (2017)

b) o foco está, totalmente, no cliente. De acordo com o gestor "o cliente fidelizado, está disposto a remunerar a qualidade de produtos e serviços, contudo em épocas de guerra de preços existe uma perda de fidelidade do cliente em até $40 \%$ do total das vendas, mesmo no produto com o diferencial competitivo de qualidade, portanto para aumentar nossa margem é necessário reduzir o custo de 
aquisição, caso contrário o posto absorve o prejuízo ou perde cliente, pois o mercado (clientes) prefere a diferenciação de custo em detrimento a diferenciação da qualidade do produto."

O gestor também afirmou "nosso contrato permite a franqueadora a fornecer o mesmo produto comercializado aos franqueados para postos bandeira branca, inclusive com menor custo ao fornecido para o meu posto".

c) deve-se levar em conta a cadeia de valor, investigando a cadeia de valor do custo do produto dos outros franqueadores tem-se no Quadro 5 os custos sem a carga tributária:

Quadro 5: Preço de custo praticados pelas distribuídoras, sem carga tributária Concorrentes

\begin{tabular}{|l|c|c|c|c|c|c|c|c|}
\hline \multicolumn{1}{|c|}{ Combustível } & Diesel & \% & Álcool & $\%$ & $\begin{array}{c}\text { Gasolina } \\
\text { Comum }\end{array}$ & $\%$ & $\begin{array}{c}\text { Gasolina } \\
\text { Aditivada }\end{array}$ & $\%$ \\
\hline Franqueadora concorrente 1 & 2,54 & $2 \%$ & 1,82 & $4 \%$ & 2,77 & $3 \%$ & 2,87 & $1 \%$ \\
\hline Franqueadora concorrente 2 & 2,42 & $7 \%$ & 1,82 & $4 \%$ & 2,71 & $5 \%$ & 2,78 & $4 \%$ \\
\hline Bandeira Branca & 2,35 & $10 \%$ & 1,77 & $6 \%$ & 2,66 & $7 \%$ & 2,67 & $8 \%$ \\
\hline Franqueadora contratual & 2,6 & $100 \%$ & 1,89 & $100 \%$ & 2,85 & $100 \%$ & 2,91 & $100 \%$ \\
\hline
\end{tabular}

Fonte: consulta ao sindicato - dados da pesquisa (2017)

Observa-se no Quadro 5 que a franqueadora da qual o posto é revendedor apresenta o maior custo de todos os concorrentes, ao apresentar esses valores ao gestor, este informou que esse é um dos agravantes contratuais, pois seu contrato não permite a livre concorrência na aquisição dos produtos então ele precisa reduzir os custos operacionais para se tornar competitivo, contudo informou que já possui a equipe enxuta e que está trabalhando na redução de custos financeiros e tributários.

O gestor também sente-se amarrado num contrato em que ele assinou quando a diferença de custos era somente de seis centavos na operação com bandeira branca e igualitária com as concorrentes. Para minimizar essa diferença, segundo o gestor, está em constante negociação com a franqueadora, contudo sem sucesso. Bem como o gestor sente-se prejudicado pois a bandeira branca citada nesse estudo, indica em suas bombas que o produto dela é adquirido da distribuidora da qual ele é franqueado.

A partir dos dados da organização analisados, observa-se mudança relevante quanto ao resultado da empresa. Nesse sentido, ressalta-se como imprescindível a consciência dos custos do negócio, uma vez que o seu desconhecimento pode levar a uma gestão ineficaz, como apresentado no caso analisado, o que resultava numa elevação dos desembolsos em tributos, por lançamentos equivocados de custos.

A análise da organização possibilitou a intervenção por meio da implan- 
tação de processos simples, mas que geram resultado de grande impacto positivo pra organização, uma vez que afetam os aspectos financeiros da empresa - revertendo a posição de prejuízo para uma condição de lucro. Foi identificada uma situação que pode ser ainda comum em empresas do segmento, o que permite sugerir a análise e possível intervenção em outros postos da região.

Neste sentido, por mais que a gestão receba influência positiva por meio de um sistema de franquia, não é suficiente para identificar lançamentos diários e pela gestão de custos da organização, que deve ser monitorada pela gestão local do empreendimento.

\section{CONSIDERAÇÕES FINAIS}

Permite-se concluir que o objetivo proposto pelo artigo foi parcialmente atingido, sendo apresentadas as intervenções aplicadas ao posto. É clara a contribuição para a organização, pois as alterações possibilitam maior fidedignidade aos lançamentos da organização. Contudo, faz-se necessário uma análise detalhada para a implementação de qual seria o custo-meta viável para a melhoria da lucratividade da empresa e atingir a meta da margem de contribuição para operar o posto e remunerar o capital investido pelos acionistas.

A identificação da margem de contribuição, da formação do preço e do lucro permitiu apresentar um panorama real da situação financeira da organização, permitindo uma visão próxima para eventuais pesquisadores que procuram conhecer mais sobre o concorrido segmento de postos de combustível. As informações levantadas pelos pesquisadores durante o desenvolvimento da pesquisa possibilitaram a tomadas de decisão de forma justificada.

Sugere-se à administração realizar novos estudos detalhados em relação aos registros contábeis, ao mesmo tempo em que se devem identificar possíveis atualizações na legislação tributária e que regulamenta o setor, no intuito de confirmar se existem ainda outras possibilidades de obtenção de vantagem competitiva por meio da adequação dos lançamentos, bem como um estudo com base na teoria dos contratos, para aproximar as diferenças de mercado uma vez que o contrato firmado é por longo prazo (média de 5 anos) e as conjuncturas economicas mudam constantemente.

Como sugestão de pesquisas futuras é a aplicação do custo-meta no posto de combustível com o intuito de estabelecer o custo máximo que poderá ser disponibilizado para desempenho das atividades. Assim, com a utilização dessa ferramenta gerencial manter-se no mercado competitivo, perseguindo a margem de lucro determinada. 


\section{REFERÊNCIAS}

ARAUJO, G. F. S. et al. O Custo Meta como estratégia empresarial. In: Congresso Brasileiro De Custos, 2004, Bahia. Anais do XI CBC, 2004.

CAMACHO, R. R.; ROCHA, W. Custeio-alvo em serviços hospitalares um estudo sob o enfoque da gestão estratégica de custos. Revista Contabilidade \& Finanças-USP, v. 19, n. 47, 2008.

CARASTAN, J. T. Custo meta e custo padrão como instrumentos do planejamento empresarial para obter vantagem competitiva. In: CONGRESSO BRASILEIRO DE CUSTOS-ABC, 23, 1999, Pernambuco. Anais... do 23 ${ }^{\circ}$ CBC, 1999.

CRUZ, C. V. O. A.; ROCHA, W. Custeio-alvo: reflexões sobre definições, finalidades e procedimentos. Revista Contemporânea de Contabilidade, v. 5, n. 10, p. 31-52, 2009.

SILVA, M. Z.; et al. Fatores contingenciais que contribuem para a decisão de modificação do sistema de custeio: estudo de caso em uma indústria moageira.

Revista de Administração, v. 49, n. 2, p. 399-414, 2014.

FERREIRA, A. C. S.; BUFONI, A. L. Fatores de sucesso e insucesso na implementação de sistemas de informação gerencial: estudo do caso do segmento de exploração e produção de petróleo da Petrobrás S/A. Revista de Administração Contemporânea, v. 10, n. 2, p. 9-31, 2006.

HANSEN, D. R.; MOWEN, M. M. Gestão de custos: contabilidade e controle. São Paulo: Pioneira Thomson Learning, 2001.

HITT, M. A.; IRELAND, R. D.; HOSKISSON, R. E. Administração estratégica. São Paulo: Pioneira Thomson Learning, 2011.

LAUSCHNER, M. A.; BEUREN, I. M. Gestão estratégica de custos. Contabilidade Vista \& Revista, v. 15, n. 2, p. 53-84, 2009.

LAVIERI, C. A.; CORRÊA, H. L.; CUNHA, J. A. C. Controle e desempenho de franquias: um estudo sobre as atividades de avaliação de desempenho organizacional realizadas por franqueadores. REGE-Revista de Gestão, v. 22, n. 3, p. 337-355, 2015. 
LEITE, A. L. S.; LANZER, E. A.; RIBEIRO SERRA, F. A.. Entre Hierarquia e Mercado: Análise da Competição no Setor de Postos de Combustíveis da Grande Florianópolis. Revista Alcance, v. 16, n. 1, 2009.

LEITE, A. L. S.; FIATES, G. G. S.; LIMA, M. A. Fatores condicionantes da vantagem competitiva nos postos de combustível de Florianópolis. REBRAERevista Brasileira de Estratégia, p. 37-44, 2013.

MARTINS, E.; ROCHA, W. Contabilidade de custos: manual do professor. São Paulo: Atlas, 2006.

MAURO, P. C. Guia do franqueado: como fazer sua empresa crescer com o franchising. 4. ed. São Paulo: Nobel, 2006.

MELO, M. A.; LEONE, R. J. G. Alinhamento entre as Estratégias Competitivas e a Gestão de Custos: Um Estudo em Pequenas Empresas Industriais do Setor de Transformação. Brazilian Business Review, v. 12, n. 5, p. 83-104, 2015.

OLIVEIRA, D. F. A Implantação de um Sistema de Gestão de Custos no Hospital Universitário pela Ebserh: Um Estudo de Caso com Utilização do PMBOK. Revista de Administração Hospitalar e Inovação em Saúde, v. 13, n. 3, p. 122-139, 2016.

PAULINO, M. L. S. Sistemas de controle administrativo no Franchising: aliando controle e flexibilidade estratégica. Revista Organizações em Contexto-online, v. 6, n. 12, p. 28-55, 2010.

PINTO, M. R.; SILVA, E. C. D. O brilho da bandeira branca: concorrência no mercado de combustíveis no Brasil. Planejamento e Políticas Públicas, v. 1, n. 31, 2009.

RAIMUNDINI, S. L.; BIANCHI, M.; ZUCATTO, L. C. Ponto de equilíbrio e otimização sob a perspectiva da matemática. Enfoque: Reflexão Contábil, v. 27, n. 2, 2008.

REDIVO, R. B. Considerações sobre o cálculo da margem de contribuição: uma proposta para inclusão do custo de reposição e do custo de oportunidade. Revista de Ciências da Administração, v. 6, n. 11, 2004. 